\title{
Perbandingan Metode Semi Average dan Metode Least Squared Pada Prediksi Penjualan Tiket Pesawat
}

\author{
Karolina Owa Sada ${ }^{1}$, Mashud $^{2}$, Muhammad Sabirin Hadis ${ }^{3}$, Bau Endang Prawati ${ }^{4}$ \\ ${ }^{1,2,3}$ STMIK AKBA, ${ }^{3,4}$ BALLA CERDAS \\ ${ }^{1}$ karolina16@mhs.akba.ac.id \\ ${ }^{2}$ mashudeakba.ac.id \\ ${ }^{3}$ muhammadsabirinhadis lakba.ac.id \\ ${ }^{4}$ bauendangprawati@gmail. com
}

\begin{abstract}
Abstrak - Penjualan tiket pesawat terkadang mengalami kenaikan atau penurunan sehingga diperlukan data prediksi yang akurat sebagai bahan pengambilan keputusan manajemen. Penelitian ini bertujuan untuk mengetahui metode prediksi yang memiliki nilai persentase kesalahan terkecil dalam memprediksi penjualan tiket pesawat pada studi kasus di PT. Perintis 77 Tours and Travel. Metode prediksi yang diuji adalah metode Semi Average dan metode Least Squared menggunakan data penjualan 1038 dengan periode penjualan Januari 2016 sampai September 2017. Data prediksi dari kedua metode tersebut dibandingkan dengan data periode penjualan asli pada bulan tersebut. Oktober 2017 hingga Desember 2017 menggunakan metode Mean Absolute Percentage Error (MAPE) untuk melihat nilai persentase kesalahan setiap metode. Hasil yang diperoleh adalah metode Semi Average dengan nilai rata-rata MAPE dalam memprediksi periode penjualan dari Oktober 2017 sampai Desember 2017 sebesar 27\%, sedangkan untuk metode Least Squared dengan periode penjualan yang sama sebesar $21,6 \%$ sehingga dapat membuktikan bahwa metode prediksi memiliki nilai persentase kesalahan terkecil dalam memprediksi penjualan tiket pesawat pada studi kasus di PT. Perintis 77 Tours and Travel merupakan metode Least Squared dengan nilai MAPE sebesar $21.6 \%$.
\end{abstract}

Kata Kunci: Prediksi Penjualan Tiket Maskapai, Metode Prediksi, Metode Semi Average; Metode Square Method, Mean Absolute Percentage Error

\section{PENDAHULUAN}

Penjualan tiket pesawat di Indonesia semakin meningkat khususnya di bulan Desember 2020 hingga Januari 2021 [1], model penjualan tiket juga sudah berkembang hingga memanfaatkan teknologi informasi dan komputer dalam operasionalnya seperti Traveloka [2] dan Tiket.com [3]. Penjualan tiket pesawat kadang mengalami peningkatan atau mengalami penurunan di setiap waktunya [4], sehingga dibutuhkan data prediksi yang tepat sebagai bahan pengambilan keputusan oleh pihak manajemen dalam meningkatkan produktifitas penjualan tiket pada perusahaannya.

Prediksi adalah suatu proses memperkirakan secara sistematis tentang sesuatu yang paling mungkin terjadi di masa depan berdasarkan informasi masa lalu dan sekarang yang dimiliki, agar kesalahannya atau selisih antara sesuatu yang terjadi dengan hasil perkiraan dapat diperkecil [5]. Selanjutnya memprediksi penjualan merupakan suatu sistem perkiraan untuk menentukan permintaan konsumen dalam periode tertentu dimasa yang akan mendatang [6].

Beberapa penelitian prediksi penjualan telah dilakukan [7] [8] [9] [10] [11], seperti penelitan prediksi penjualan tahu menggunakan metode Least Square [12] menjelaskan bahwa salah satu perusahaan produksi tahu di daerah Jawa Timur seringkali mengalami kerugian karena jumlah produksi tahu lebih banyak dibandingkan dengan jumlah penjualannya. Oleh karena itu perlu adanya suatu sistem yang dapat memprediksi penjualan setiap harinya. Sistem prediksi yang dibuat menggunakan metode Least Square, selanjutnya peneliti menggunakan teori Correlation untuk mengetahui korelasi antara data hasil prediksi dengan data asli hasil penjualan. Didapatkan hasil dari penelitian tersebut bahwa prediksi penjualan tahu menggunakan metode Least Square mendapatkan hasil nilai korelasi sebesar 0,88 sehingga disimpulkan metode tersebut dapat digunakan.

Penelitian selanjutnya terkait dengan prediksi penjualan kompor gas menggunakan metode Semi Average [13] menjelaskan bahwa data latih yang digunakan merupakan data penjualan kompor gas selama enam tahun, yaitu mulai dari tahun 2012 hingga tahun 2017. Selanjutnya data uji yang digunakan adalah data penjualan tahun 2018. Didapatkan hasil bahwa perhitungan prediksi menggunakan metode Semi Average adalah 1.183 unit kompor terjual dengan data asli penjualan di tahun yang sama sebesar 1.200 unit, sehingga ada selisih 17 unit yang menjadi error pada model prediksi tersebut.

Selanjutnya terkait dengan penelitian prediksi penjualan tiket pesawat menggunakan metode Least Square [14] yang bertujuan untuk mengetahui prediksi penjualan tiket pesawat Kalstar pada Perusahaan Daerah Witeltram Kabupaten Kutai Barat dari tahun 2015 sampai dengan tahun 2019 mengalami peningkatan atau penurunan, peneliti memiliki hipostesis bahwa penjualan akan meningkat pada periode tersebut. Didapatkan hasil bahwa metode analisis Least Square menunjukkan prediksi angka penjualan meningkat pada periode tahun 2015 sampai dengan tahun 2019 sehingga hipotesis dari peneliti dapat diterima.

Berdasarkan latar belakang yang telah diuraikan, maka penelitian ini bertujuan untuk membandingkan metode Semi Average dan metode Least Square dalam memprediksi penjualan tiket pesawat sehingga dapat diketahui metode yang memiliki tingkat akurasi lebih baik diantara kedua metode tersebut.

Artikel penelitian ini terdiri dari beberapa bagian yaitu, bagian I memaparkan tentang pendahuluan, bagian II menjelaskan tentang metode penelitian yang terdiri dari tahapan penelitian yang dilakukan, penjelasan model metode Semi Average, Least Squared dan Mean Absolute Percentage Error (MAPE), bagian III membahas hasil penelitian yang telah dilakukan, dan bagian IV merupakan kesimpulan dari hasil penelitian yang telah didapatkan.

\section{METODE}

Pembahasan pada bagian II menjelaskan tahapan-tahapan penelitian yang dilakukan untuk mencapai tujuan penelitian, selanjutnya membahas metode Semi Average dan Least Square yang digunakan dalam memprediksi data penjualan tiket pesawat serta metode MAPE untuk menguji akurasi kedua metode prediksi yang digunakan berdasarkan presentase. 


\section{A. Tahapan Penelitian}

Tahap-tahap yang dilakukan pada penelitian ini dimulai dari mengambil data penjualan tiket pesawat di PT. Perintis 77 Tours and Travel dengan menggunakan data penjualan dimulai dari bulan Januari tahun 2016 sampai dengan bulan Desember tahun 2017. Untuk Data latih yang digunakan dimulai dari bulan Januari tahun 2016 sampai dengan bulan September tahun 2017 sebanyak 1038 data penjualan, selanjutnya yang dijadikan sebagai data uji dimulai dari bulan Oktober tahun 2017 sampai dengan Desember tahun 2017.

Setelah mendapatkan data yang akan digunakan, selanjutnya kami memilih metode Semi Average dan metode Least Square sebagai metode yang akan digunakan untuk memprediksi penjualan tiket pesawat. Hasil prediksi dari metode Semi Average dan metode Least Square akan dibandingkan untuk mengetahui metode yang terbaik dalam memprediksi penjualan tiket pesewat dengan menggunakan metode Mean Absolute Percentage Error (MAPE). Berikut gambar 1 menjelaskan alur penelitian yang dikerjakan.

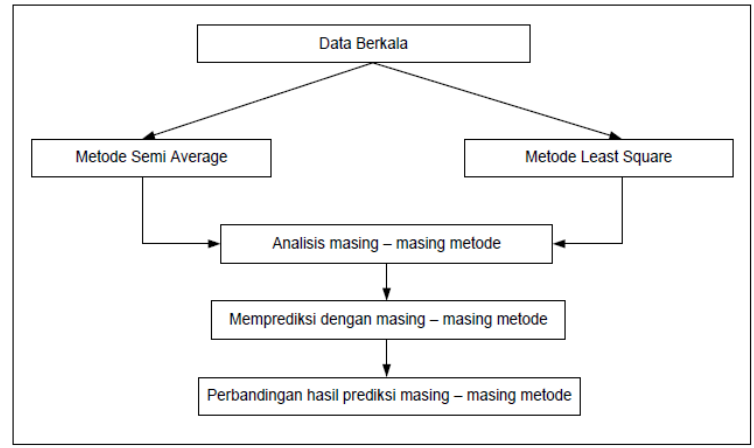

Gambar 1. Alur Penelitian

\section{B. Metode Semi Average}

Perhitungan dari metode Semi Average [15] dapat dijabarkan dengan menentukan persamaan garis trend $\mathrm{Y}^{\prime}=\mathrm{a}+\mathrm{b}(\mathrm{x})$. Langkah pertama data ganjil: hilangkan satu data yaitu data yang berada paling tengah, bagi data menjadi dua data dengan jumlah data yang sama. Pada cara ini digunakan data latih selama 21 bulan dari bulan Januari tahun 2016 sampai dengan September tahun 2017. Model analisis data Semi Average menggunakan data penjualan selama 21 bulan dapat dilihat pada Tabel 1 . Tabel 1. Model Analisis Data Semi Average

\begin{tabular}{|c|c|c|}
\hline Data Ganjil & Variabel Waktu & Kelompok \\
\hline $\mathrm{x}_{1}$ & 0 & \multirow{10}{*}{ Kelompok I } \\
\hline$x_{2}$ & 1 & \\
\hline$x_{3}$ & 2 & \\
\hline$x_{4}$ & 3 & \\
\hline$x_{5}$ & 4 & \\
\hline$x_{6}$ & 5 & \\
\hline$x_{7}$ & 6 & \\
\hline$x_{8}$ & 7 & \\
\hline$x_{9}$ & 8 & \\
\hline$x_{10}$ & 9 & \\
\hline$x_{11}$ & 10 & Dihilangkan \\
\hline$x_{12}$ & 11 & \multirow{10}{*}{ Kelompok II } \\
\hline$x_{13}$ & 12 & \\
\hline$x_{14}$ & 13 & \\
\hline$x_{15}$ & 14 & \\
\hline$x_{16}$ & 15 & \\
\hline$x_{17}$ & 16 & \\
\hline$x_{18}$ & 17 & \\
\hline$x_{19}$ & 18 & \\
\hline$x_{20}$ & 19 & \\
\hline$x_{21}$ & 20 & \\
\hline
\end{tabular}

Dimana kelompok I berjumlah 10 data yaitu X1 sampai dengan $\mathrm{X} 10$ dan variabel waktu yaitu 0 sampai 9 . Kelompok II berjumlah 10 data yaitu X12 sampai dengan X21 dan variabel waktu yaitu 11 sampai dengan 20. Langkah kedua adalah memilih titik absis yang berada di tengah masing-masing kelompok. Misalkan X1 dan X2 dimana kelompok I data X5 dan X6 adalah data tengah yang berada diantara kedua data tersebut. Kelompok II data X16 dan X17 adalah data tengah yang berada diantara kedua data tersebut. X1 pada kelompok I sama dengan 4.5 diperoleh dari menghitung nilai median. X2 kelompok II sama dengan 15.5 diperoleh dari menghitung nilai median. Langkah ketiga memilih titik ordinat atau masing-masing kelompok dicari rata-ratanya, misalkan Y1 dan Y2.

Tabel 2. Analisis Data Titik Ordinat (Y) Semi Average

\begin{tabular}{|c|c|c|c|}
\hline Data Ganjil & $\begin{array}{l}\text { Variabel } \\
\text { Waktu }\end{array}$ & Kelompok & Titik Ordinat $(\mathrm{Y})$ \\
\hline$Y_{1}$ & 0 & \multirow{10}{*}{ Kelompok I } & \multirow{10}{*}{$\overline{\mathrm{Y} 1}=\frac{\mathrm{Y}_{1}+\mathrm{Y}_{2}+\mathrm{Y}_{3}+\mathrm{Y}_{4}}{4}$} \\
\hline$Y_{2}$ & 1 & & \\
\hline$Y_{3}$ & 2 & & \\
\hline$Y_{4}$ & 3 & & \\
\hline$Y_{5}$ & 4 & & \\
\hline$Y_{6}$ & 5 & & \\
\hline$Y_{7}$ & 6 & & \\
\hline$Y_{8}$ & 7 & & \\
\hline$Y_{9}$ & 8 & & \\
\hline$Y_{10}$ & 9 & & \\
\hline$Y_{11}$ & 10 & Dihilangkan & \multirow{11}{*}{$\overline{Y 2}=\frac{Y 5+Y 6+Y 7+Y 8}{4}$} \\
\hline$Y_{12}$ & 11 & \multirow{10}{*}{ Kelompok II } & \\
\hline$Y_{13}$ & 12 & & \\
\hline$Y_{14}$ & 13 & & \\
\hline$Y_{15}$ & 14 & & \\
\hline$Y_{16}$ & 15 & & \\
\hline$Y_{17}$ & 16 & & \\
\hline$Y_{18}$ & 17 & & \\
\hline$Y_{19}$ & 18 & & \\
\hline$Y_{20}$ & 19 & & \\
\hline$Y_{21}$ & 20 & & \\
\hline
\end{tabular}

Dimana Y1 adalah untuk mencari nilai rata-rata kelompok I dan Y2 adalah untuk mencari nilai rata-rata kelompok II. Langkah keempat adalah masukkan titik (X1, Y1) dan (X2, Y2) ke dalam persamaan $\mathrm{Y}^{\prime}=\mathrm{a}+\mathrm{b}(\mathrm{x})$, selanjutnya langkah kelima adalah menghitung nilai $a$ dan $b$ dan yang terakhir langkah keenam, jika didapatkan nilai a dan b maka dapat diketahui persamaan $\mathrm{Y}$.

C. Metode Least Square

Perhitungan dari metode Least Square [16] dapat dijabarkan dengan menentukan persamaan garis trend $\mathrm{Y}^{\prime}=\mathrm{a}+\mathrm{bX}$. Dimana $\mathrm{Y}^{\prime}$ sama dengan data Berkala (Time Series Data), a sama dengan nilai konstanta saat $\mathrm{t}$ sama dengan 0 , b sama dengan kemiringan garis, $\mathrm{X}$ sama dengan variabel waktu (hari, minggu, bulan dan tahun). Model analisis data Least Square menggunakan data penjualan selama 21 bulan dapat dilihat pada Tabel 3 .

Tabel 3. Analisis Data Ganjil Least Square

\begin{tabular}{|c|c|}
\hline Data Ganjil & Variabel Waktu \\
\hline$X_{1}$ & -10 \\
\hline$X_{2}$ & -9 \\
\hline$X_{3}$ & -8 \\
\hline$X_{4}$ & -7 \\
\hline$X_{5}$ & -6 \\
\hline$X_{6}$ & -5 \\
\hline$X_{7}$ & -4 \\
\hline$X_{8}$ & -3 \\
\hline$X_{9}$ & -2 \\
\hline$X_{10}$ & -1 \\
\hline$X_{11}$ & 0 \\
\hline$X_{12}$ & 1 \\
\hline$X_{13}$ & 2 \\
\hline$X_{14}$ & 3 \\
\hline$X_{15}$ & 4 \\
\hline$X_{16}$ & 5 \\
\hline$X_{17}$ & 6 \\
\hline$X_{18}$ & 7 \\
\hline$X_{19}$ & 8 \\
\hline$X_{20}$ & 9 \\
\hline$X_{21}$ & 10 \\
\hline & \\
\hline & \\
\hline
\end{tabular}

Untuk mencari persamaan trend garis lurus dengan metode ini dapat dilakukan sebagai berikut dengan langkah pertama mengadakan perhitungan diperlukan nilai tertentu pada variabel 
waktu (X) atau periode waktu setiap bulan, dan jumlah nilai variabel waktu $(\mathrm{X})$ adalah nol, atau $\Sigma \times=0$. Dalam menentukan nilai $\mathrm{X}$ dengan melihat jumlah data yaitu data ganjil dan data genap, untuk tahun dasar ditengah-tengah data, karena data yang digunakan adalah data dalam jumlah ganjil. Berikut rumus data ganjil. Untuk n ganjil:

$$
\mathrm{n}=2 \mathrm{k}+1 \leftrightarrow \mathrm{k}=\frac{n-1}{2} ; \mathrm{X}_{\mathrm{k}+1}=0
$$

Dimana jarak antara dua waktu diberi nilai satu-satuan, nilai satuan waktu diatas 0 diberi tanda (+) positif, nilai satuan waktu dibawah 0 diberi tanda (-) negatif. Perhitungan $n=21$ bulan maka:

$$
\mathrm{n}=21 \rightarrow \mathrm{k}=\frac{n-1}{2}=\frac{21-1}{2}=10 \rightarrow \mathrm{X}_{10+1}=\mathrm{X}_{11}=0
$$

Langkah kedua mencari nilai a dan b menggunakan rumus berikut:

$$
\begin{gathered}
a=\bar{Y}=\frac{\sum Y i}{n} \\
b=\frac{\sum X i Y i}{\sum X i^{2}}
\end{gathered}
$$

Langkah ketiga adalah persamaan garis lurus Y sudah diketahui.

D. Perhitungan Nilai Akurasi dari Hasil Prediksi

Untuk menghitung nilai akurasi hasil prediksi, penelitian ini menggunakan metode Mean Absolute Percentage Error (MAPE) [17] yang merupakan perhitungan menggunakan rata-rata kesalahan absolute prediksi dalam bentuk persentasenya terhadap data aktualnya. MAPE digunakan untuk mengevaluasi peramalan mengunakan kesalahan dalam bentuk persentase. Semakin kecil nilai MAPE berarti nilai taksiran semakin mendekati nilai sebenarnya, atau metode yang dipilih merupakan metode terbaik. Perhitungan rata-rata kesalahan dengan MAPE biasanya lebih banyak dan mudah dibaca dikarenakan dalam bentuk persentase. Nilai MAPE dapat dihitung dengan persamaan berikut:

$$
M A P E=\frac{\sum_{t=1}^{n}\left|\frac{X t-F t}{X t}\right|}{n} x 100 \%
$$

Dimana Xt adalah data aktual pada periode t, Ft sama dengan nilai peramalan pada periode $t$, dan $n$ sama dengan jumlah data, serta $t$ sama dengan periode $\mathrm{ke}-\mathrm{t}$.

\section{HASIL DAN PEMBAHASAN}

Setelah menjelaskan rumusan metode yang akan digunakan pada bagian dua, maka hasil penelitian dan pembahasan dibagi menjadi dua, yaitu:

A. Hasil Prediksi menggunakan metode Semi Average

Langkah pertama adalah menentukan $\mathrm{X}$ atau periode waktu setiap bulan dari bulan Januari tahun 2016 sampai dengan budang September tahun 2017 yang dirumuskan pada Tabel 4. Setelah menentukan $\mathrm{X}$ yang harus diketahui nilai a dan $\mathrm{b}$ sebagai berikut:

$$
\text { b }=\frac{\text { Semi Average II-Semi Average I }}{n}
$$

Semi Average I sama dengan 428/10 didapatkan nilai 42.8 dan Semi Average II sama dengan 540/10 didapatkan nilai 54, dan

\begin{tabular}{|c|c|c|c|}
\hline Bulan & Data Tiket (Y) & Kel & (X) \\
\hline Januari 2016 & 32 & \multirow{10}{*}{ kel I } & 0 \\
\hline Februari 2016 & 50 & & 1 \\
\hline Maret 2017 & 45 & & 2 \\
\hline April 2016 & 23 & & 3 \\
\hline Mei 2016 & 17 & & 4 \\
\hline Juni 2016 & 40 & & 5 \\
\hline Juli 2016 & 82 & & 6 \\
\hline Agustus 2016 & 20 & & 7 \\
\hline September 2016 & 30 & & 8 \\
\hline Oktober 2016 & 89 & & 9 \\
\hline November 2016 & 70 & Dihilangkan & 10 \\
\hline Desember 2016 & 80 & \multirow{10}{*}{ kel II } & 11 \\
\hline Januari 2017 & 20 & & 12 \\
\hline Februari 2017 & 40 & & 13 \\
\hline Maret 2017 & 80 & & 14 \\
\hline April 2017 & 10 & & 15 \\
\hline Mei 2017 & 100 & & 16 \\
\hline Juni 2017 & 20 & & 17 \\
\hline Juli 2017 & 70 & & 18 \\
\hline Agustus 2017 & 40 & & 19 \\
\hline September 2017 & 80 & & 20 \\
\hline
\end{tabular}
nilai a adalah 42.8 , maka:

$$
\mathrm{b}=\frac{54-42,8}{10}=1,12
$$

Dengan diketahui nilai a dan $b$, maka didapat persamaan:

$$
Y^{\prime}=42,8+1,12(x)
$$

Tabel 4. Perhitungan Metode Semi Average

Setelah mendapat persamaan, maka didapatkan nilai prediksi penjualan tiket pada bulan Oktober tahun 2017 adalah 66 tiket. Model perumusan dapat dilihat pada gambar 2.

$$
\begin{aligned}
& \text { Persamaan } Y^{\prime}=42,8+1,12(x) . \\
& \text { Bulan Oktober tahun } 2017, x=21 \\
& Y^{\prime}=42,8+1,12(21) \\
& =42,8+23,52 \\
& =66,32
\end{aligned}
$$

Gambar 2. Rumusan Hasil Prediksi Bulan Oktober 2017

Untuk nilai prediksi penjualan tiket pada bulan November tahun 2017 adalah 67 tiket. Model perumusan dapat dilihat pada gambar 3.

$$
\begin{aligned}
& \text { Persamaan } Y^{\prime}=42,8+1,12(x) \\
& \text { Bulan November } 2017, x=22 \\
& Y^{\prime}=42,8+1,12(22) \\
& =42,8+24,64 \\
& =67,44
\end{aligned}
$$

Gambar 3. Rumusan Hasil Prediksi Bulan November 2017

Selanjutnya nilai prediksi penjualan tiket pada bulan Desember tahun 2017 adalah 68 tiket. Model perumusan dapat dilihat pada gambar 4. 


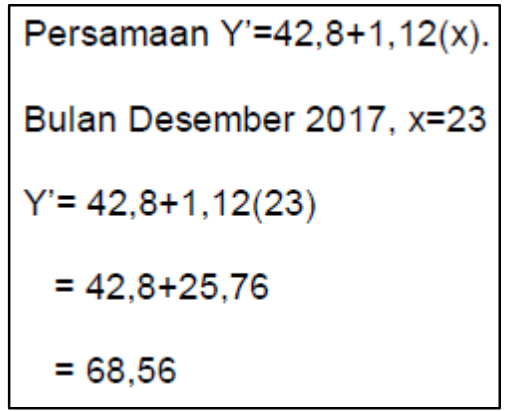

Gambar 4. Rumusan Hasil Prediksi Bulan Desember 2017

Setelah mendapat nilai prediksi, maka selanjutnya dilakukan perhitungan perbandingan nilai keakuratan dari Metode Semi Average dengan mencari nilai MAPE. Nilai MAPE pada hasil prediksi bulan Oktober tahun 2017 adalah 40\%. Model perumusan dapat dilihat pada gambar 5 .

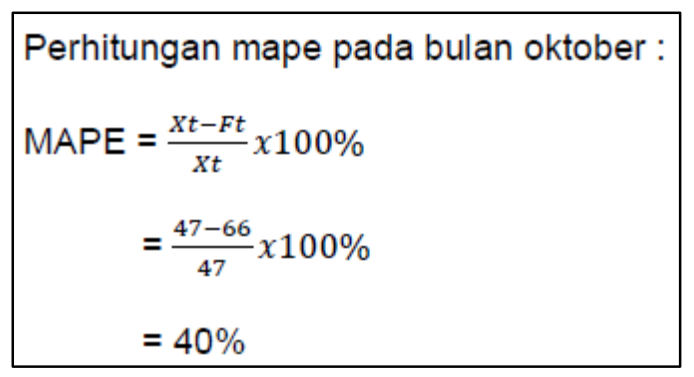

Gambar 5. Rumusan Hasil MAPE Bulan Oktober 2017

Untuk nilai MAPE pada hasil prediksi bulan November tahun 2017 adalah 34\%. Model perumusan dapat dilihat pada gambar 6.

$$
\begin{aligned}
& \text { Perhitungan mape pada bulan november : } \\
& \begin{aligned}
\text { MAPE } & =\frac{x t-F t}{x t} \times 100 \% \\
& =\frac{50-67}{50} \times 100 \% \\
& =34 \%
\end{aligned}
\end{aligned}
$$

Gambar 6. Rumusan Hasil MAPE Bulan November 2017

Selanjutnya nilai MAPE pada hasil prediksi bulan Desember tahun 2017 adalah 7\%. Model perumusan dapat dilihat pada gambar 7.

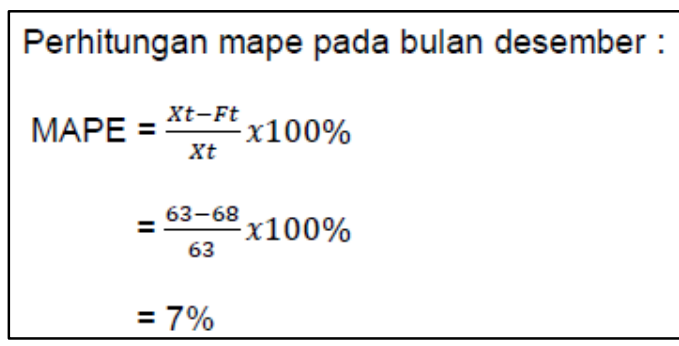

Gambar 7. Rumusan Hasil MAPE Bulan Desember 2017

Perbandingan data asli dengan data prediksi pada penjualan tiket pesawat menggunakan metode Semi Average dapat dilihat pada tabel 5 .
Tabel 5. Hasil Nilai MAPE pada metode Semi Average

\begin{tabular}{|c|c|c|c|}
\hline Bulan & Data Asli & Data Prediksi & MAPE \\
\hline Oktober 2017 & 47 & 66 & $40 \%$ \\
\hline November 2017 & 50 & 67 & $34 \%$ \\
\hline Desember 2017 & 63 & 68 & $7 \%$ \\
\hline
\end{tabular}

B. Hasil Prediksi menggunakan metode Least Square

Langkah pertama adalah menentukan $\mathrm{X}$ atau periode waktu untuk setiap bulan yang dirumuskan pada tabel 6 .

Tabel 6. Perhitungan Metode Least Square

\begin{tabular}{|c|c|c|}
\hline Bulan & Data Tiket (Y) & $\mathbf{X}$ \\
\hline Januari 2016 & 32 & -10 \\
\hline Februari 2016 & 50 & -9 \\
\hline Maret 2017 & 45 & -8 \\
\hline April 2016 & 23 & -7 \\
\hline Mei 2016 & 17 & -6 \\
\hline Juni 2016 & 40 & -5 \\
\hline Juli 2016 & 82 & -4 \\
\hline Agustus 2016 & 20 & -3 \\
\hline September 2016 & 30 & -2 \\
\hline Oktober 2016 & 89 & -1 \\
\hline November 2016 & $\mathbf{7 0}$ & $\mathbf{0}$ \\
\hline Desember 2016 & 80 & 1 \\
\hline Januari 2017 & 20 & 2 \\
\hline Februari 2017 & 40 & 3 \\
\hline Maret 2017 & 80 & 4 \\
\hline April 2017 & 10 & 5 \\
\hline Mei 2017 & 100 & 6 \\
\hline Juni 2017 & 20 & 7 \\
\hline Juli 2017 & 70 & 8 \\
\hline Agustus 2017 & 40 & 9 \\
\hline September 2017 & 80 & 10 \\
\hline Jumlah & 1038 & - \\
\hline
\end{tabular}

Setelah menentukan $\mathrm{X}$ yang harus diketahui adalah nilai a dan b dengan model a sama dengan $\left(\sum \mathrm{Y}\right) / \mathrm{n}$. Maka a sama dengan 1038/21 didapatkan hasil 49,42. Sedangkan untuk mencari nilai b digunakan rumus $\mathrm{b}$ sama dengan $\left(\sum X Y\right) / \sum \mathrm{x} 2$, setelah itu mencari nilai dari $\sum \mathrm{XY}$ yang dibagi dengan nilai $\sum \mathrm{x} 2$ didapatkan hasil b sama dengan 940/770 sama dengan 1,22. Dari nilai a dan $b$ maka dapat diketahui persamaan $Y^{\prime}=49,42+1,22 X$.

Setelah mendapat persamaan, maka didapatkan nilai prediksi penjualan tiket pada bulan Oktober tahun 2017 adalah 63 tiket. Model perumusan dapat dilihat pada gambar 8 .

Untuk nilai prediksi penjualan tiket pada bulan November tahun 2017 adalah 64 tiket. Model perumusan dapat dilihat pada gambar 9 .

Selanjutnya nilai prediksi penjualan tiket pada bulan Desember tahun 2017 adalah 65 tiket. Model perumusan dapat dilihat pada gambar 10 .

Setelah mendapat nilai prediksi, maka selanjutnya dilakukan perhitungan perbandingan nilai keakuratan dari metode Least Square dengan mencari nilai MAPE. Nilai MAPE pada hasil prediksi bulan Oktober tahun 2017 adalah 34\%. Model perumusan dapat dilihat pada gambar 11 .

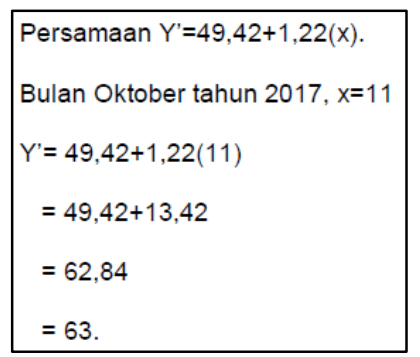

Gambar 8. Rumusan Hasil Prediksi Bulan Oktober 2017 


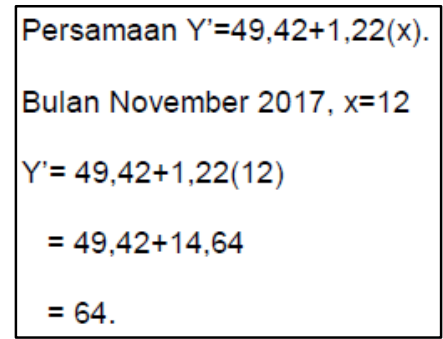

Gambar 9. Rumusan Hasil Prediksi Bulan November 2017

Persamaan $Y^{\prime}=49,42+1,22(x)$.
Bulan Desember $2017, x=13$
$Y^{\prime}=49,42+1,22(13)$
$=49,42+15,86$
$=65,28$
$=65$.

Gambar 10. Rumusan Hasil Prediksi Bulan Desember 2017

$$
\begin{aligned}
& \text { Perhitungan mape pada bulan oktober : } \\
& \begin{aligned}
\text { MAPE } & =\frac{X t-F t}{x t} \times 100 \% \\
& =\frac{47-63}{47} \times 100 \% \\
& =34 \%
\end{aligned}
\end{aligned}
$$

Gambar 11. Rumusan Hasil MAPE Bulan Oktober 2017

Untuk nilai MAPE pada hasil prediksi bulan November tahun 2017 adalah 28\%. Model perumusan dapat dilihat pada gambar 12

Selanjutnya nilai MAPE pada hasil prediksi bulan Desember 2017 adalah 3\%. Model perumusan dapat dilihat pada Gambar 13.

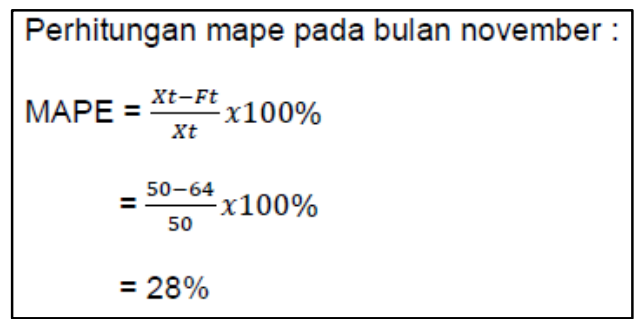

Gambar 12. Rumusan Hasil MAPE Bulan November 2017

$$
\begin{aligned}
& \text { Perhitungan mape pada bulan desember : } \\
& \begin{aligned}
\text { MAPE } & =\frac{X t-F t}{x t} x 100 \% \\
& =\frac{63-65}{63} x 100 \% \\
& =3 \%
\end{aligned}
\end{aligned}
$$

Gambar 13. Rumusan Hasil MAPE Bulan Desember 2017
Perbandingan data asli dengan data prediksi pada penjualan tiket pesawat menggunakan metode Least Square dapat dilihat pada tabel 7 .

Tabel 7. Hasil Nilai MAPE pada metode Least Square

\begin{tabular}{|c|c|c|c|}
\hline Bulan & Data Asli & Data Prediksi & MAPE \\
\hline Oktober 2017 & 47 & 63 & $34 \%$ \\
\hline November 2017 & 50 & 64 & $28 \%$ \\
\hline Desember 2017 & 63 & 65 & $3 \%$ \\
\hline
\end{tabular}

\section{Hasil Perbandingan Metode}

Setelah menguji metode Semi Average dan metode Least Square untuk memprediksi data penjualan tiket pesawat di bulan Oktober tahun 2017 sampai dengan Desember tahun 2017 didapatkan hasil bahwa rata-rata presentase error pada metode Semi Average sebesar $27 \%$ sedangkan untuk metode Least Square didapatkan hasil rata-rata presentase error sebesar $21,6 \%$ sehingga metode yang memiliki nilai rata-rata presentase error terkecil dalam memprediksi penjualan tiket pesawat adalah metode Least Square dengan nilai error hanya sebesar 21,6\%. Tabel 8 memperlihatkan data perbandingan kedua metode dan pada gambar 14 memperlihatkan grafik perbandingan nilai MAPE pada kedua metode yang diuji.

Tabel 8. Perbandingan Nilai MAPE

\begin{tabular}{|c|c|c|c|}
\hline Bulan & $\begin{array}{c}\text { MAPE } \\
\text { Semi Average }\end{array}$ & $\begin{array}{c}\text { MAPE } \\
\text { Least Squared }\end{array}$ & Selisih \\
\hline Oktober 2017 & $40 \%$ & $34 \%$ & $6 \%$ \\
\hline November 2017 & $34 \%$ & $28 \%$ & $6 \%$ \\
\hline Desember 2017 & $7 \%$ & $3 \%$ & $4 \%$ \\
\hline Rata - Rata MAPE & $\mathbf{2 7 \%}$ & $\mathbf{2 1 . 6 \%}$ & $\mathbf{5 . 4 \%}$ \\
\hline
\end{tabular}

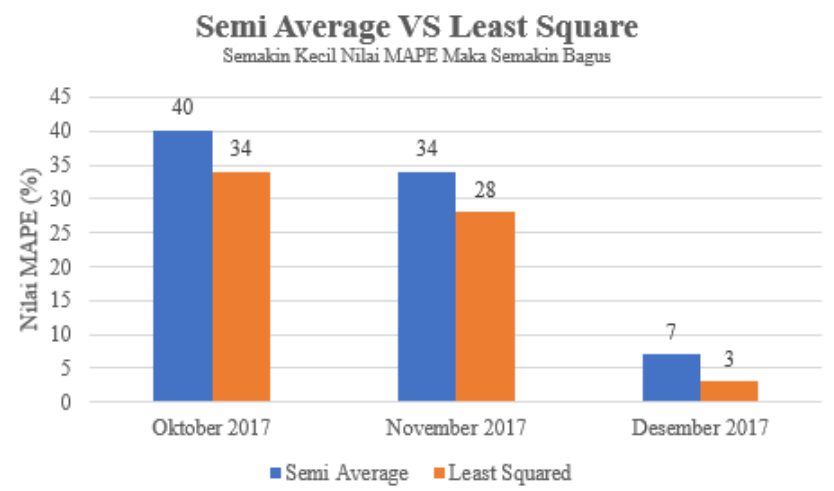

Gambar 14. Perbandingan Nilai MAPE

\section{PENUTUP}

\section{A. Kesimpulan}

Dari hasil pengujian yang telah dilakukan sesuai dengan penjelasan pada bagian III, maka dapat disimpulkan bahwa metode prediksi yang paling baik diantara kedua metode yang diuji dalam memprediksi pejualan tiket pesawat adalah metode Least Square dengan keunggulan di semua data uji mulai dari bulan Oktober tahun 2017 dengan nilai MAPE sebesar 34\% dibandingkan metode Semi Average sebesar 40\%, bulan November tahun 2017 dengan nilai MAPE sebesar 28\% dibandingkan metode Semi Average sebesar 34\%, dan data terakhir bulan Desember tahun 2017 dengan nilai MAPE sebesar 3\% dibandingkan metode Semi Average sebesar 7\% sehingga nilai rata-rata MAPE untuk Least Square adalah 21,6\% dibandingkan metode Semi Average sebesar $27 \%$. 


\section{B. Saran}

Untuk penelitian selanjutnya disarankan untuk melakukan perbandingan metode-metode prediksi dengan model studi kasus yang sama dengan harapan menemukan metode prediksi yang lebih baik dibandingkan metode Least Square yang telah diuji pada penelitian ini.

\section{DAFTAR PUSTAKA}

[1] "Penjualan Tiket Pesawat Naik Signifikan." https://www.katakini.com/artikel/40068/penjualan-tiketpesawat-naik-signifikan/ (accessed Jan. 08, 2021).

[2] "Traveloka.com - The No. 1 solution for all your travel needs." https://www.traveloka.com/en-id/ (accessed Jan. 08, 2021).

[3] "tiket.com - Satu Aplikasi untuk Kebutuhan Liburanmu." https://www.tiket.com/ (accessed Jan. 08, 2021).

[4] Pergi.com, "Kenapa Harga Tiket Pesawat Naik Turun?," Medium, Feb. 22, 2017. https://medium.com/pergi$\mathrm{com} /$ kenapa-harga-tiket-pesawat-naik-turun-2773c28450f4 (accessed Jan. 05, 2021).

[5] Herdianto, "PREDIKSI KERUSAKAN MOTOR INDUKSI MENGGUNAKAN METODE JARINGAN SARAF TIRUAN BACKPROPAGATION," Universitas Sumatera Utara, Medan, 2013.

[6] A. M. Idhofi, "PERAMALAN PENJUALAN TIKET PESAWAT PADA CV. VIDO JAYA TOUR DAN TRAVEL," Universitas Gunadarma, Depok, 2015.

[7] M. Aritonang and D. J. C. Sihombing, "An Application of Backpropagation Neural Network for Sales Forecasting Rice Miling Unit," in 2019 International Conference of Computer Science and Information Technology (ICoSNIKOM), Medan, Indonesia, Nov. 2019, pp. 1-4, doi: 10.1109/ICoSNIKOM48755.2019.9111612.

[8] M. O. Erboy, N. Bulut, S. Shakeri, S. Yuzuk, and M. S. Aktas, "Company Sales Prediction and Stock Exhance Investor Profit Prediction based on Company Balance Sheet Data," in 2019 4th International Conference on Computer Science and Engineering (UBMK), Samsun, Turkey, Sep. 2019, pp. 201-205, doi: 10.1109/UBMK.2019.8907132.

[9] L. Huang, Z. Dou, Y. Hu, and R. Huang, "Online Sales Prediction: An Analysis With Dependency SCOR-Topic Sentiment Model," IEEE Access, vol. 7, pp. 79791-79797, 2019, doi: 10.1109/ACCESS.2019.2919734.

[10] Y. Liang et al., "Online Shop Daily Sale Prediction Using Adaptive Network-Based Fuzzy Inference System," in 2019 12th International Congress on Image and Signal Processing, BioMedical Engineering and Informatics (CISP-BMEI), Suzhou, China, Oct. 2019, pp. 1-6, doi: 10.1109/CISP-BMEI48845.2019.8966058.

[11] V. C. Sugiarto, R. Sarno, and D. Sunaryono, "Sales forecasting using Holt-Winters in Enterprise Resource Planning at sales and distribution module," in 2016 International Conference on Information \& Communication Technology and Systems (ICTS), Surabaya, Indonesia, 2016, pp. 8-13, doi: 10.1109/ICTS.2016.7910264.

[12] D. P. Pamungkas, "Implementasi Metode Least Square Untuk Prediksi Penjualan Tahu Pong," Netw. Eng. Res. Oper., vol. 2, no. 2, 2016.

[13] S. Patandean, A. Askar, and M. Mashud, "APLIKASI FORECASTING PENJUALAN MENGGUNAKAN METODE SEMI AVERAGE PADA TOKO RUMAH
KITA MAKASSAR," Inspir. J. Teknol. Inf. Dan Komun., vol. 9, no. 1, pp. 25-32, Jun. 2019.

[14] A. Jariah, T. Militina, and E. A.Lau, "Penjualan Tiket Pesawat Kalstar Pada Perusahaan Daerah Witeltram Kabupaten Kutai Barat," Ekonomia, vol. 5, no. 1, pp. 360366, 2016

[15] Q. A. Ar Ruhimat, Belajar Statistika - Analisis Data Berkala part1 Metode Tangan Bebas Metode Rata-Rata Semi. 2020.

[16] Q. A. Ar Ruhimat, Belajar Statistika - Analisis Data Berkala part3 Metode Kuadrat Terkecil (metode least square). 2020.

[17] A. I. Cahyani, "Sistem Pendukung Keputusan Peramalan Pendapatan Di Dinas Penanaman Modal Dan Pelayanan Perizinan Terpadu Satu Pintu Kabupaten Buleleng Dengan Metode Least Square," Urnal Nas. Pendidik. Tek. Inform. JANAPATI, vol. 7, no. 1, pp. 1-11, 2018. 